1. MBBS, FCPS

Senior Registrar Cardiology Faisalabad Institute of Cardiology, Faisalabad.

2. MCPS (Medicine), FCPS (Card.) Associate Professor Cardiology Faisalabad Institute of Cardiology, Faisalabad.

3. MBBS, Dip Card. (Gold Medalist) Consultant Cardiologist

Faisalabad Institute of Cardiology, Faisalabad.

4. MCPS (Medicine),

FCPS (Cardiology)

Assistant Professor Cardiology

Faisalabad Institute of Cardiology,

Faisalabad.

5. MBBS, FCPS

Senior Registrar Cardiology

Faisalabad Institute of Cardiology,

Faisalabad.

6. MBBS, FCPS

Senior Registrar Cardiology

Faisalabad Institute of Cardiology,

Faisalabad.

Correspondence Address:

Dr. Naeem Hameed

Department of Cardiology

Faisalabad Institute of Cardiology,

Faisalabad.

dr_naeem80@hotmail.com

Article received on:

13/05/2020

Accepted for publication:

15/09/2020

\title{
Risk factors for coronary artery disease among judicial officers.
}

Naeem Hameed ${ }^{1}$, Shahid Abbas ${ }^{2}$, Faisal Ali $^{3}$, Muhammad Akram ${ }^{4}$, Shahid Iqbal ${ }^{5}$, Ali Farahe ${ }^{6}$

ABSTRACT... Objectives: This study was to find out the prevalence of risk factors for coronary artery disease in very important group of population who are expected to have sedentary lifestyle. Study Design: Cross-Sectional study. Setting: Faisalabad Institute of Cardiology, Faisalabad. Period: January 2015 to June 2017. Material \& Methods: Officers from age of 25 years to 60 years and of either sex were enrolled in study. FLP, FBS, BP, weight and height were measured at FIC. Frequency of coronary artery disease risk factors including Diabetes, HTN, smoking, dyslipidemia, physical activity and obesity was noted considering diagnostic criteria. Results: Mean age was $40.86 \pm 7.49,84.4 \%(n=76)$ were male, $15.6 \%(n=14)$ were females, $11.1 \%(n=10)$ were diabetic, $88.9 \%(n=80)$ were non-diabetic, 4 were known case of ischemic heart disease with one having CABG. Smoking was present in $27.8 \%(n=25)$. Hypertension was found in $22.2 \%(n=20)$. LDL cholesterol was raised in $24.4 \%(n=22)$ officers. $46.7 \%(n=42)$ were having high BMI i.e.>25. A high proportion was found to have sedentary lifestyle with $72.2 \%(n=65)$ being physically less active. Conclusion: Major conventional Risk factors for coronary artery disease are prevalent in young healthy judicial officers who were not patient of any significant disease.

Key words: $\quad$ Coronary Artery Disease, Fasting Blood Sugar, Hypertension, Obesity, Smoking.

Article Citation: Hameed N, Abbas S, Ali F, Akram M, lqbal S, Farahe A. Risk factors for coronary artery disease among judicial officers. Professional Med J 2020; 27(12):2591-2595. https://doi.org/10.29309/TPMJ/2020.27.12.4790

\section{INTRODUCTION}

Though cardiovascular disease is major cause of morbidity and mortality worldwide but $75 \%$ of its lethal effect is in low-middle income countries. ${ }^{1}$ Along with many other risk factors, ethnicity is also an important indicator of future development of CAD. ${ }^{2}$ And different communities in the same ethnicity can have variable prevalence of Disease depending on its risk factors. Presence of these risk factors depend on the type of profession, type of duties, working hours, stress level, accompanying population and accessibility to healthcare facility.

Traditional risk factors for Coronary artery disease including Smoking, Diabetes, Hypertension, dyslipidemia, physical activity, dietary habits and psychosocial stress are important modifiable factors which need attention in every community and profession to explore its prevalence and accordingly need of preventive strategy to avoid Ischemic heart disease in relevant subgroup of population.

Smoking and exposure to second hand smoke leads to significant number of premature deaths according to $1^{\text {st }}$ surgeon general's report. ${ }^{3}$ Smoking causes $32 \%$ of coronary heart disease deaths. Use of tobacco products is increasing globally with almost $80 \%$ of world's smokers living in low- and middle-income countries. ${ }^{4}$ In Pakistan, $33 \%$ of men and $4 \%$ of women are found to have smoking. ${ }^{5}$ Tobacco is used for smoking mainly which is basic harmful product and is used in various other forms also. It is a causative factor for CAD whether used in smoke or smokeless form.

Diabetes, one of the most common chronic diseases in the world affected $285 \mathrm{~m}$ adults in 
$2010 .{ }^{6}$ It is estimated that diabetes will affect more then $430 \mathrm{~m}$ persons by $2030 .^{6}$ Hyperglycemia leads to endothelial vasomotor dysfunction, vascular affects of advanced glycation end products, increased systemic inflammation and prothrombotic state. Out of these the $1^{\text {st }}$ one is the hallmark of diabetic cardiovascular disease. Timely identification and Optimal strategies to control diabetes is very important to avoid its cardiovascular effects.

Systolic BP above 130 and diastolic BP above 80 is termed hypertension which is present in over 1 billion worldwide population. ${ }^{7}$ Hypertension causes 7.6 million premature deaths worldwide annually, with $80 \%$ of this burden occurring in low and middle income countries. ${ }^{8}$ Risk factors for development of Hypertension include ethnicity, family history, increasing age, genetic factors, lower education, psychosocial stressors, tobacco use, sedentary lifestyle, increased weight, sleep apnea and dietary habits. Development of hypertension also coincides with development of hyperglycemia. $^{9}$

Dyslipidemia is very established risk factor for cardiovascular disease with LDL cholesterol significantly linked to $\mathrm{MI}$ and cardiovascular death. ${ }^{10} \mathrm{HDL}$ is $2^{\text {nd }}$ important agent with increase of $1 \mathrm{mg} / \mathrm{dl} \mathrm{HDL}$ levels are associated with 2 to $3 \%$ decrease in total CV death.

Regarding physical activity, it is said that inactivity can cause similar number of deaths as smoking. ${ }^{11}$ Heart healthy guidelines recommend that adults should have 150 minutes per week of moderate intensity physical activity. Obesity is one additional factor associated with CAD. It is becoming serious health problem worldwide. ${ }^{12}$ It is quite difficult to treat after it has developed. ${ }^{13}$ Obesity alone is associated with all cause mortality regardless of physical activity. ${ }^{14}$ Considering all these factors as the most important contributors of cardiovascular disease, we decided to conduct study in very important sub-population who have quite less physical activity and are expected to be more prone to develop coronary artery disease. Frequency of risk factors will clear the attention they needed to improve primary preventive strategies if existing are not sufficient.

\section{MATERIAL \& METHODS}

This Cross-sectional study was conducted at Faisalabad institute of cardiology, from January 2015 to June 2017 with 95\% confidence interval and absolute precision of $8 \%$. Judicial officers of age 25 to 60 years, of either sex, with ongoing service, presenting to FIC for general evaluation were included in study.

After approval from hospital Ethical committee Faisalabad Institute of Cardiology, total 90 judicial officers were enrolled. Procedure of research was explained to the patients and informed consent was taken. Smoking is labelled if anyone has smoked 100 cigarettes throughout life and last cigarette in last 28 days. Hypertensive is labeled when BP is more than $130 / 80$ on 2 different occasions or already on antihypertensive medication. Diabetes is based on blood sugar levels if more than 126 fasting or more than 200 random blood levels or those taking medicine for diabetes with normal blood sugar levels. Obesity was labeled on BMI. Physical activity was assessed either as sedentary or active lifestyle. Demographic data and required information were collected through prescribed proforma.

Data was analyzed by SPSS-25. Quantitative variable like age was calculated by mean and standard deviation. Qualitative variables like gender, Presence of hypertension, diabetes, smoking, obesity, dyslipidemia, physical activity presented in the form of frequencies and percentages. Effect modifiers like age, and gender were stratified to control its effect on outcome variables. Post stratification chi-square test was applied. $\mathrm{P}$ value $\leq \mathbf{0 . 0 5}$ was considered significant.

\section{RESULTS}

A total of 90 judicial officers were enrolled fulfilling the inclusion and exclusion criteria. Mean age was $40.86 \pm 7.49,84.4 \%(n=76)$ were male, $15.6 \%$ $(n=14)$ were females, $11.1 \%(n=10)$ were diabetic, $88.9 \%(n=80)$ were non-diabetic. Majority of the diabetics were taking oral hypoglycemic agents with well controlled diabetes. 4 were known case 
of ischemic heart disease with one having CABG. Out of these four patients, one had PCl 5 years back. Smoking was present in $27.8 \%(n=25)$. $24.4 \%$ have smoking of more than 1pack per day. Hypertension was found in $22.2 \%(n=20)$. It was uncontrolled in 2 officers. Others were taking antihypertensive medications with good compliance and control. LDL cholesterol was raised in $24.4 \%(n=22)$ officers. Two of them were found to have levels more than $190 \mathrm{mg} / \mathrm{dl}$. Rest were having levels between 150 to $190 \mathrm{mg} /$ dl. $46.7 \%(n=42)$ were having high BMl i.e. $>25$.
Obesity was further divided into overweight, mild, moderate and severe obesity and morbidly obese patients. It was found that $2.2 \%(n=2)$ were morbidly obese. $17.8 \%(n=16)$ were overweight, $15.6 \%(n=14)$ had mild obesity, $6.7 \%(n=6)$ had moderate obesity with BMl between 35 to 39.9. and $6.7 \%(n=6)$ were morbidly obese with BMI above 40. A high proportion was found to have sedentary lifestyle with $72.2 \%(n=65)$ being physically less active.

\begin{tabular}{|c|c|c|c|c|}
\hline \multirow{2}{*}{ Characteristics } & \multirow{2}{*}{$n=81$} & \multicolumn{2}{|c|}{ Gender } & \multirow{2}{*}{ P-Value } \\
\hline & & Male & Female & \\
\hline Age & $40.86 \pm 7.49$ & $84.4 \%(76)$ & $15.6 \%(14)$ & \\
\hline HTN & $22.2 \%(20)$ & $23.7 \%(18)$ & $14.3 \%(2)$ & 0.443 \\
\hline Obesity & $56.7 \%(42)$ & $44.7 \%(34)$ & $57.14 \%(8)$ & 0.398 \\
\hline Smoking & $27.8 \%(25)$ & $28.9 \%(22)$ & $21.4 \%(3)$ & 0.569 \\
\hline Physical activity & $27.8 \%(n=25)$ & $27.6 \%(n=21)$ & $28.6 \%(4)$ & .943 \\
\hline
\end{tabular}

\section{DISCUSSION}

CAD risk factors either modifiable or nonmodifiable, are of immense significance as their control is the primary goal of treatment in patients who have developed CAD and for prevention of those who have not entered into the red zone yet. Along with other risk factors, age is very important single factor as we see CAD in old age patients without any other contributing condition. Many studies have supported this fact. ${ }^{15}$ And it is the most common factor as everybody will definitely get advanced age if living. Mean age of our population was 40 years which itself carries moderate risk of ischemic heart disease if anyone has atypical chest pain.

Among modifiable risk factors, we found, obesity as the most common factor in our evaluated population. BMI is the most commonly used measure of obesity. ${ }^{16}$ Obesity was $56.7 \%$ in our population. Based on NHANES data USA had $37.7 \%$ prevalence of obesity overall in year 2013, 2014. ${ }^{17}$ We had higher prevalence which might be because of the nature of work our community has. They have long sessions of sitting which may contribute to their obesity. Obesity is the $5^{\text {th }}$ leading risk of death worldwide and it has well recognized association with diabetes as among obese patients, $44 \%$ patients have diabetes. ${ }^{18}$

Second most common risk factor found in our community was lack of physical activity. Smoking had similar prevalence as of physical activity. Both are said to be equally dangerous risk factor for CAD. 27.8\% judicial officers had sedentary lifestyle and similar number were smokers. In PROMIS study (Pakistan risk of Myocardial Infarction) it was found to be $9 \%$ in general population who did not have CAD. ${ }^{19}$ Others were having moderate or heavy physical activity. In PURE-HIS study, 27.2\% male and $17.2 \%$ female were found to have low level of physical activity. ${ }^{20}$ It was again nature of job which contributes to the low level of physical activity. Our population found higher prevalence of sedentary lifestyle causing this population to be at higher risk of coronary artery disease.

Smoking being well known risk factor for CAD was $27.8 \%$ in judicial officers. This was bit less than those found in PROMIS study (32\%) in controls. An 
Indian study showed $30 \%$ prevalence of smoking in urban population of Bangalore and Delhi. ${ }^{21}$ It was found to be $20.8 \%$ in Karachi. ${ }^{22}$ Diabetes is quite common in our society. CARRS study found it to be $16.3 \%$ in Karachi and $22.8 \%$ in Chennai. ${ }^{23}$ Our study found $11.1 \%$ prevalence of diabetes which was lower than that found in CARRS study. This was most probably due to relatively younger population in our study. Sri Lankan population was found to have $12.6 \%$ diabetes. $^{24}$

Hypertension is another important modifiable risk factor for CAD. It was found to be $22.2 \%$. Prevalence of Hypertension was $16.3 \%$ in a study conducted by Rastogi and collegues. ${ }^{25}$ Hypertension have many contributing factors as it is associated with lack of rest, psychosocial stress, increased salt intake and sedentary lifestyle along with dietary habits. Our population has more prevalence because of nature of job and some dietary habits which contribute to HTN. Dyslipidemia was also higher in our population being $24.4 \%$. Increased level of LDL cholesterol is most important for CAD. It was more prevalent in those with sedentary lifestyle.

\section{CONCLUSION}

Judicial officers being important subset of society should have better lifestyle and best form of primary preventive strategies. To evaluate the weightage of risk factors in this population we conducted study in judicial officers working in Faisalabad. We found higher prevalence of common risk factors than general population here in Pakistan as well as other Asian countries. This is most probably due to their nature of job. But whatever the reason is, our aim is to control CAD. With the help of our study we are able to better guide that how much attention this community needs for prevention of coronary artery disease. Copyright(C) 15 Sep, 2020.

\section{REFERENCES}

1. World Health Organization. Global status report on non-communicable disease 2014.
2. Patel SA, Deepa M, Shivashankar R, Ali MK, Kapoor D, Gupta R, Lall D, Tandon N, Mohan V, Kadir MM, Fatmi Z. Comparison of multiple obesity indices for cardiovascular disease risk classification in South Asian adults: The CARRS Study. PLoS One. 2017 Apr 27;12(4):e0174251. https://doi.org/10.1371/journal. pone.0174251.

3. US Centers for Disease Control and Prevention. The health consequences of smoking-50 years of progress: A report of the Surgeon General. 2014.

4. World Health Organization. WHO report on the global tobacco epidemic, 2013: Enforcing bans on tobacco advertising, promotion and sponsorship. 2013.

5. Alam AY, lqbal A, Mohammad KB, Laporte RE, Ahmed A, Nishtar S. Investigating socioeconomic-demographic determinants of tobacco use in Rawalpindi, Pakistan. BMC Public Health. 2008; 8:50.

6. Shaw JE, Sicree RA, Zimmet PZ. Global estimates of the prevalence of diabetes for 2010 and 2030. Diabetes Res Clin Pract. 2010; 87:4-14.

7. James PA, Oparil S, Carter BL, et al. 2014 Evidencebased guideline for the management of high blood pressure in adults: Report from the panel members appointed to the Eighth Joint National Committee (JNC 8). JAMA. 2014; 311(5):507-520.

8. Ibrahim MM, Damasceno A. Hypertension in developing countries. Lancet. 2012; 380:611-619.

9. Ferrannini E, Cushman WC. Diabetes and hypertension: The bad companions. Lancet. 2012; 380:601-610.

10. Ridker PM. LDL cholesterol: Controversies and future therapeutic directions. Lancet. 2014; 384:607-617.

11. Lee IM, Shiroma EJ, Lobelo F, et al. Effect of physical inactivity on major non-communicable diseases worldwide: An analysis of burden of disease and life expectancy. Lancet. 2012; 380:219-229.

12. Flegal KM, Kruszon-Moran D, Carroll MD, et al. Trends in obesity among adults in the United States, 2005 to 2014. JAMA. 2016; 315:2284-2291.

13. Fothergill E, Guo J, Howard L, et al. Persistent metabolic adaptation 6 years after "The Biggest Loser" competition. Obesity (Silver Spring). 2016; 24:1612-1619.

14. Villareal DT, Chode S, Parimi N, et al. Weight loss, exercise, or both and physical function in obese older adults. N Engl J Med. 2011; 364:1218-1229. 
15. Asia Pacific Cohort Studies Collaboration. Body mass index and cardiovascular disease in the Asia-Pacific Region: an overview of 33 cohorts involving $\mathbf{3 1 0} \mathbf{0 0 0}$ participants. International journal of epidemiology. 2004 Aug 1;33(4):751-8. https://doi. org/10.1093/ije/dyh163.

16. Popkin BM, Slining MM. New dynamics in global obesity facing low- and middle-income countries. Obes Rev. 2013; 14: 11-20. https://doi.org/10.1111/ obr.12102 PMID: 24102717.

17. Flegal KM, Kruszon-Moran D, Carroll MD, et al. Trends in obesity among adults in the United States, 2005 to 2014. JAMA. 2016; 315:2284-2291.

18. World Health Organization. Obesity and overweight fact sheet. 2016.

19. Saleheen D, Zaidi M, Rasheed A, et al. The Pakistan risk of myocardial infarction study: A resource for the study of genetic, lifestyle and other determinants of myocardial infarction in South Asia. Eur J Epidemiol. 2009; 24 (6):329-33810.1007/s10654-009-9334-y.

20. Chomitz VR, Prabhu SS, Thanikachalam S, et al. Physical activity and sedentary behavior in South Indian adults: Urbanicity, gender, and obesity. FASEB J. 2013;27.
21. Rastogi T, Reddy KS, Vaz M, et al. Diet and risk of ischemic heart disease in India. Am J Clin Nutr. 2004; 79(4):582-592.

22. Berg CJ, Ajay VS, Ali MK, et al. A cross-sectional study of the prevalence and correlates of tobacco use in Chennai, Delhi, and Karachi: Data from the CARRS study. BMC Public Health. 2015; 15:48310.1186/ s12889-015-1817-z.

23. Deepa M, Grace M, Binukumar B, et al. High burden of prediabetes and diabetes in three large cities in South Asia: The center for cArdio-metabolic risk reduction in South Asia (CARRS) study. Diabetes Res Clin Pract. 2015; 110 (2):172-18210.1016/j.diabres. 2015.09.005.

24. Katulanda P, Constantine GR, Mahesh JG, et al. Prevalence and projections of diabetes and prediabetes in adults in Sri Lanka-Sri Lanka Diabetes, Cardiovascular Study (SLDCS). Diabet Med. 2008; 25(September (9)):1062-1069.

25. Rastogi T, Jha P, Reddy KS, et al. Bidi and cigarette smoking and risk of acute myocardial infarction among males in urban India. Tob Control. 2005; 14 (5):356-35810.1136/tc. 2005.011965.

\begin{tabular}{|c|c|c|c|}
\hline \multicolumn{4}{|c|}{ AUTHORSHIP AND CONTRIBUTION DECLARATION } \\
\hline Sr. \# & Author(s) Full Name & Contribution to the paper & Author(s) Signature \\
\hline 1 & Naeem Hameed & Manuscript writing. & (101200) \\
\hline 2 & Shahid Abbas & Data analysis. & \\
\hline 3 & Faisal Ali & Editing. & Taisal \\
\hline 4 & Muhammad Akram & Data collection. & Ahrow \\
\hline 5 & Shahid Iqbal & References. & sumisne \\
\hline 6 & Ali Farahe & Proof reading. & (iey \\
\hline
\end{tabular}

